\title{
Actinomycotic Infection of Spine - A Rare Disease with Diagnostic Challenge, an Update on Spinal Infection
}

\author{
Shailesh Hadgaonkar ${ }^{1}$, Pradhyumn Rathi ${ }^{1}$, Vivek Vincent ${ }^{1}$, Ashok Shyam ${ }^{1}$, Parag Sancheti ${ }^{1}$ \\ Learning Point of the Article: \\ Actinomycotic Spinal infections often mimic tuberculosis, hence should be definitively diagnosed.
}

\section{Abstract}

Introduction: We are reporting a rare case of lumbar spinal actinomycosis with superficial discharging sinuses in an elderly female.

Case Report: A 56-year-old female came in outpatient with chief complaints of low back pain radiating to both buttocks, burning sensations to both lower limbs. Magnetic resonance imaging (MRI) re-vealed signal intensity changes suggestive of patchy marrow edema present over the L2 to $\mathrm{S} 1$ vertebra. Surgery was performed in the form of laminectomy and decompression by posterior approach and tissue was collected from right sacral ala. Contrast MRI showed patchy areas of marrow signal ab-normality L1, L2, L4, and L5 vertebra and adjoining end plates of L5, S1, and S2 segments. Ring en-hancing lesions at L2 and L3 levels. The patient underwent revision surgery. Histopathology revealed clumps of basophilic filamentous bacteria in a vaguely rosette-like configuration surrounded by acute inflammatory cells, characteristic of actinomycosis.

Conclusion: Actinomycotic infections of spine are a rare cause of spinal infections but should be kept in mind once the tubercular infection is ruled out. The definitive diagnosis of actinomycosis can be made by finding actinomycetes in the pus from affected tissue.

Keywords: Actinomycosis, epidural abscess, laminectomy, magnetic resonance imaging, spinal cord compression.

\section{Introduction}

Spinal epidural abscess has an estimated incidence rate of $0.2-2.8 / 10,000$ per year with incidence mainly in the age group of $60-70$ years [1]. Spinal epidural abscess due to actinomycosis is a rare af-fection and poses a diagnostic challenge to differentiate actinomycosis from other affections of epi-dural abscess $[2,3,4]$. Actinomycosis can affect people of all ages, but the majority of cases are re-ported in young to middle-aged adults (aged 20-50 years). Men are affected more commonly than women, with the exception of pelvic actinomycosis. The reported male-to-female ratio is 3:1 [5]. Causative risk factors for epidural abscess can be due to acquired immunodeficiency, alcoholism, poor oral hygiene and dentition, chronic renal failure, diabetes mellitus, intravenous drug abuse, malignancy, spinal procedure or surgery, and spinal trauma [6].
We are reporting a rare case of lumbar spinal actinomycosis with superficial discharging sinuses in an elderly female.

\section{Case Report}

A 56-year-old female came in outpatient with chief complaints of low back pain radiating to both but-tocks, burning sensations to both lower limbs. She had a claudication distance of $<100 \mathrm{~m}$. She also complained of weakness in both feet and difficulty to put footwear. Her back VAS was 7 and leg VAS was 8. Her ODI was 74 . She gave a history of constitutional symptoms such as loss of weight and appetite. Trial of conservative management was given at multiple hospitals.

Clinical examination revealed bilateral SLR test positive at $30^{\circ}$. Her neurological examination showed grade 3 weakness in both toe and ankle dorsiflexors. Sensations across the bilateral L4 and

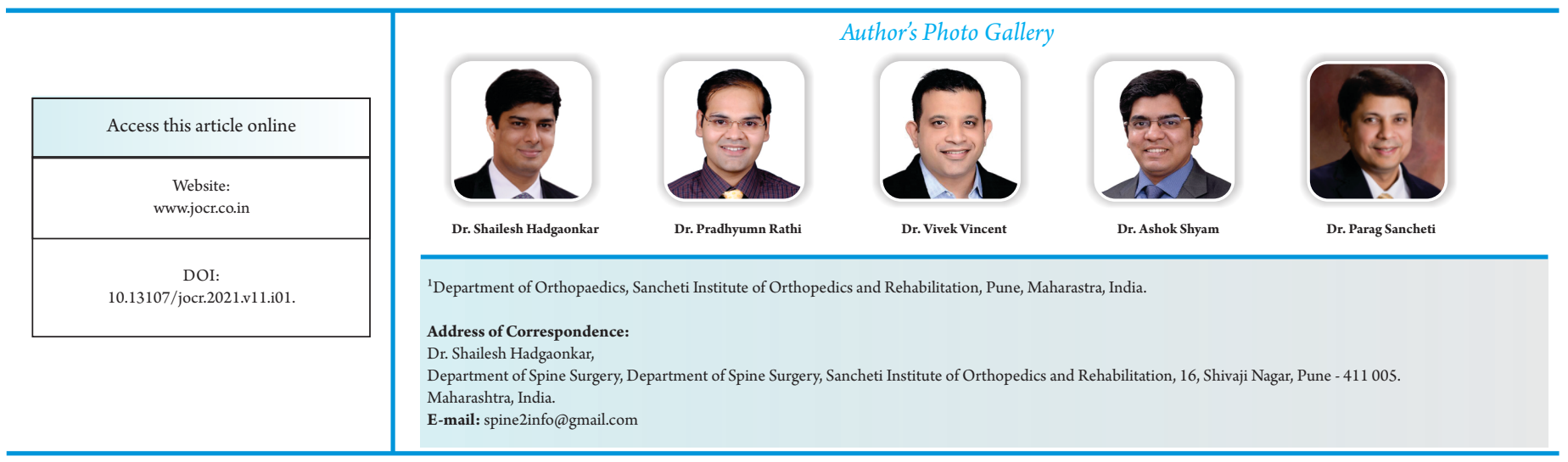

Journal of Orthopaedic Case Reports | pISSN 2250-0685 | eISSN 2321-3817 | Available on www.jocr.co.in | doi:10.13107/jocr.2021.v11.i01. This is an Open Access article distributed under the terms of the Creative Commons Attribution Non-Commercial License (http://creativecommons.org/licenses/by-nc/3.0) which permits unrestricted non-commercial use, distribution, and reproduction in any medium, provided the original work is properly cited. 


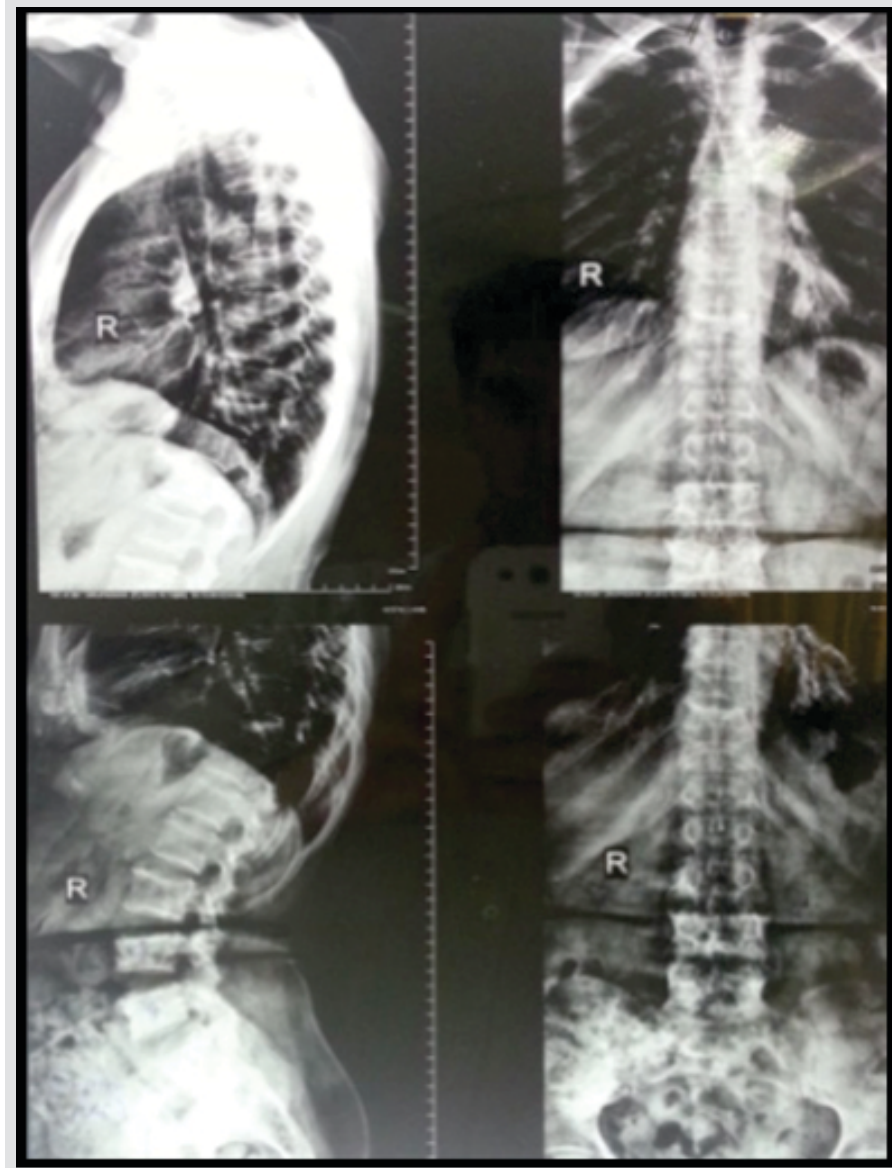

Figure 1: Lumbar spine X-ray revealed paradiscal osteopenia with decreased disc space between Ls and $\mathrm{S} 1$.

L5 derma-tomes were reduced by $50 \%$.

Her white blood cell count was 11,000, ESR was 10, and CRP was 45. Radiologically, lumbar spine X-ray (Fig. 1) revealed pars discal osteopenia with decreased disc space between L5 and S1.

Magnetic resonance imaging (MRI) (Fig. 2) revealed signal intensity changes suggestive of patchy marrow edema present over the L2 to S1 vertebra up to the upper two-third of the sacral ala, mid por-tion of sacrum, and right iliac bone with associated epidural, pre- and paravertebral soft-tissue exten-sion along bilateral psoas muscles suggestive of infective etiology rather than neoplastic.

While a nuclear positron emission tomography (PET) scan (Fig. 3) showed an increase in radiotracer concentration involving L2-L5 vertebra, S1 vertebra, right Sacroiliac region,

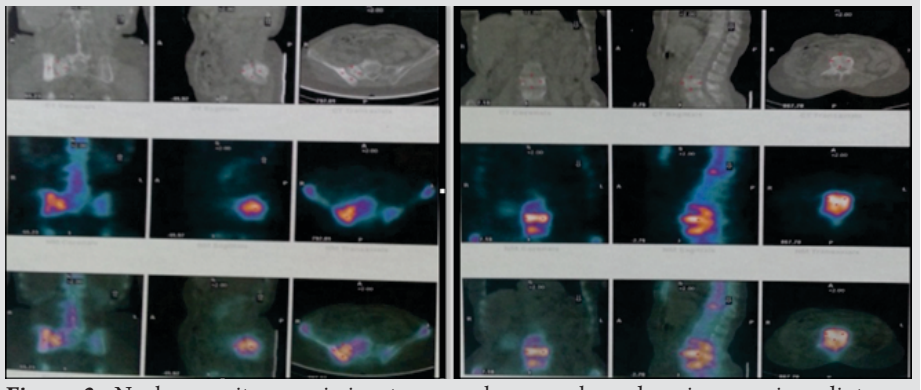

Figure 3: Nuclear positron emission tomography scan showed an increase in radiotracer concentration involving L2-L5 vertebra, S1 vertebra, right sacroiliac region, and right ilium.

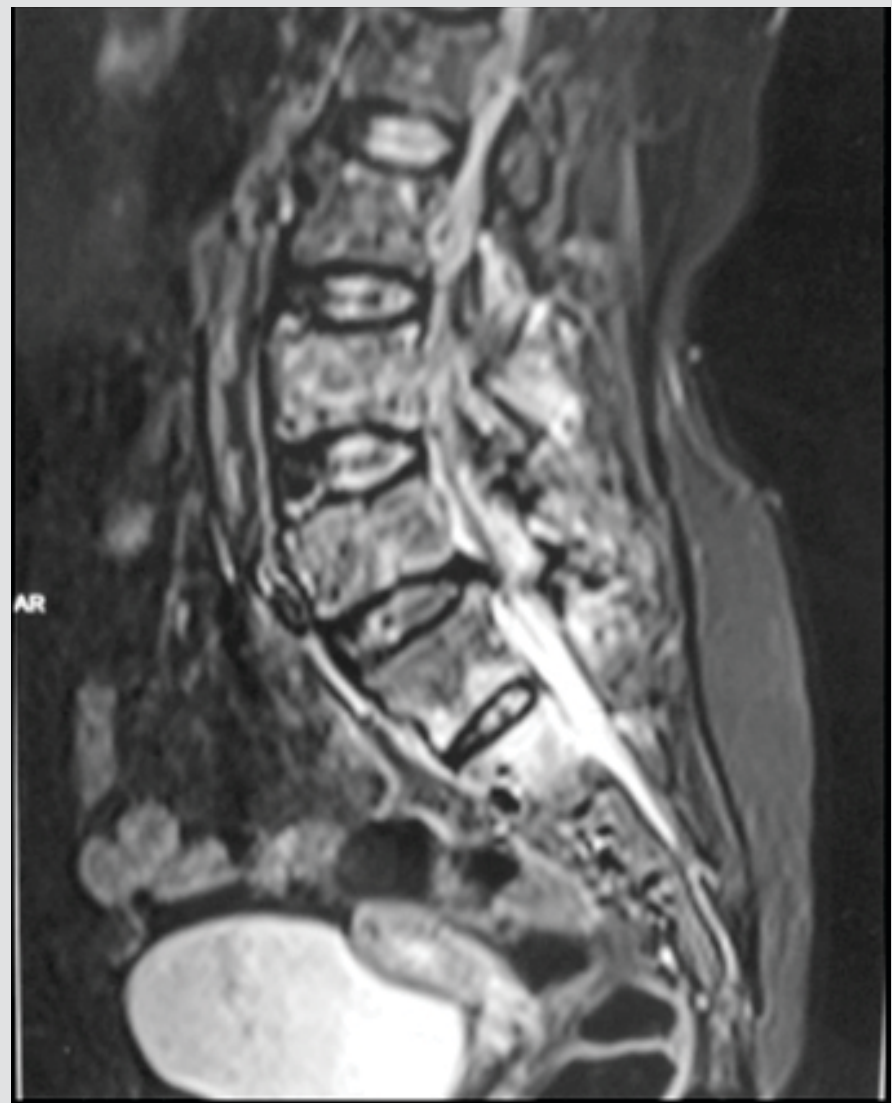

Figure 2: Magnetic resonance imaging revealed signal intensity changes suggestive of patchy marrow edema present over the L2 to S1 vertebra up to the upper two-third of the sacral ala, midportion of sacrum and right iliac bone with associated epidural, pre- and paravertebral soft-tissue extension along bilateral psoas muscles.

and right ilium, which favored a metastatic etiology rather than infection, leading to a diagnostic dilemma.

In view of persistent neurological deficit, pain, a team discussion with oncologists, infectious disease specialists, and orthopedic spine team, the final decision was made to do a

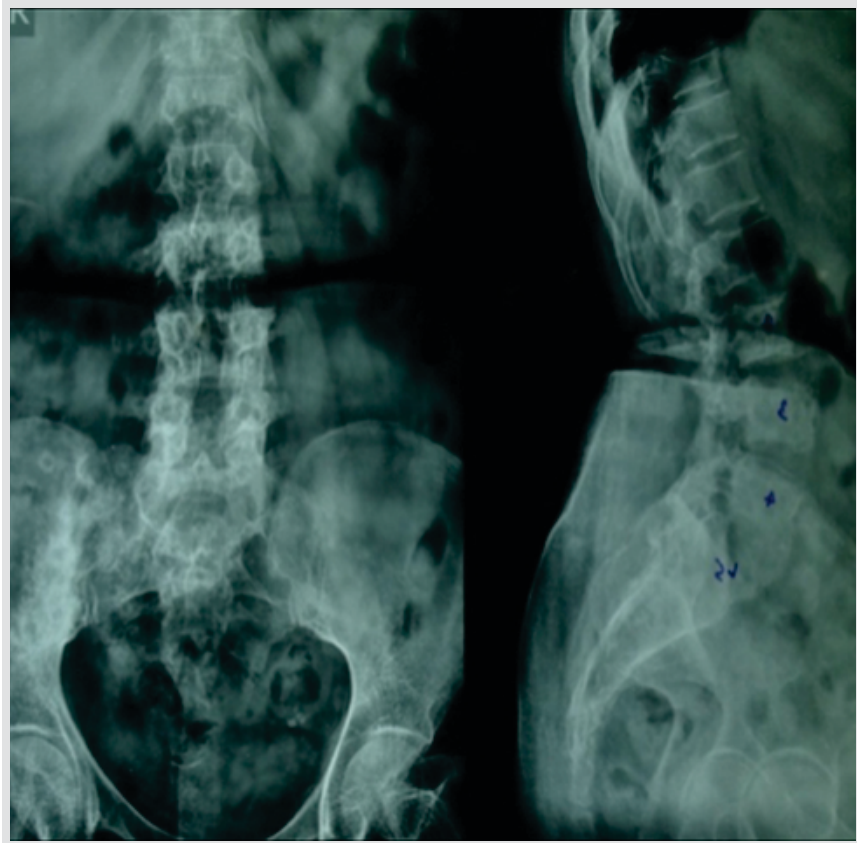

Figure 4: X-ray revealed diffuse osteopenia with patchy sclerosis and degenerative changes with lami-nectomy defects. 


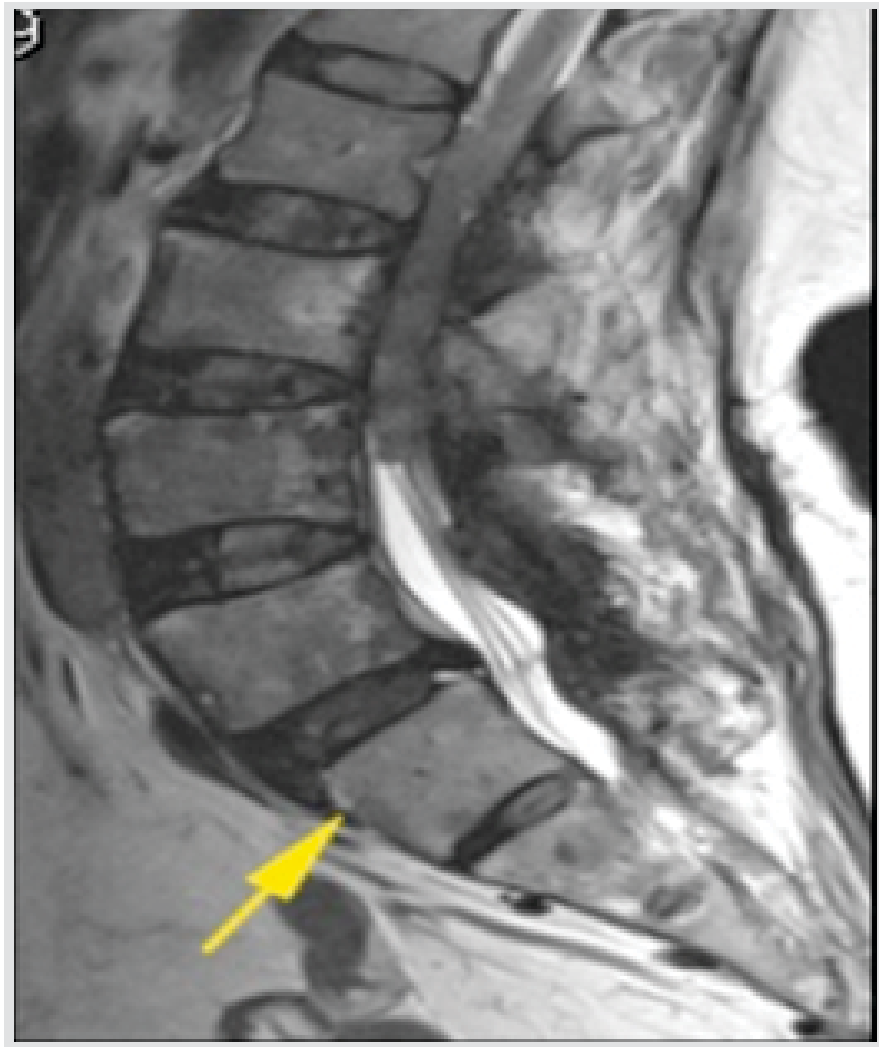

Figure 5: Contrast magnetic resonance imaging showed patchy areas of marrow signal abnormality L1, L2, L4, and L5 vertebra and adjoining endplates of L5, S1, and S2 segments. Ring enhancing lesions at L2, L3 levels. Enhancing hyperintense signals in posterior paraspinal muscles at L1 and L2. Tiny enhancing lesions on the right ilium.

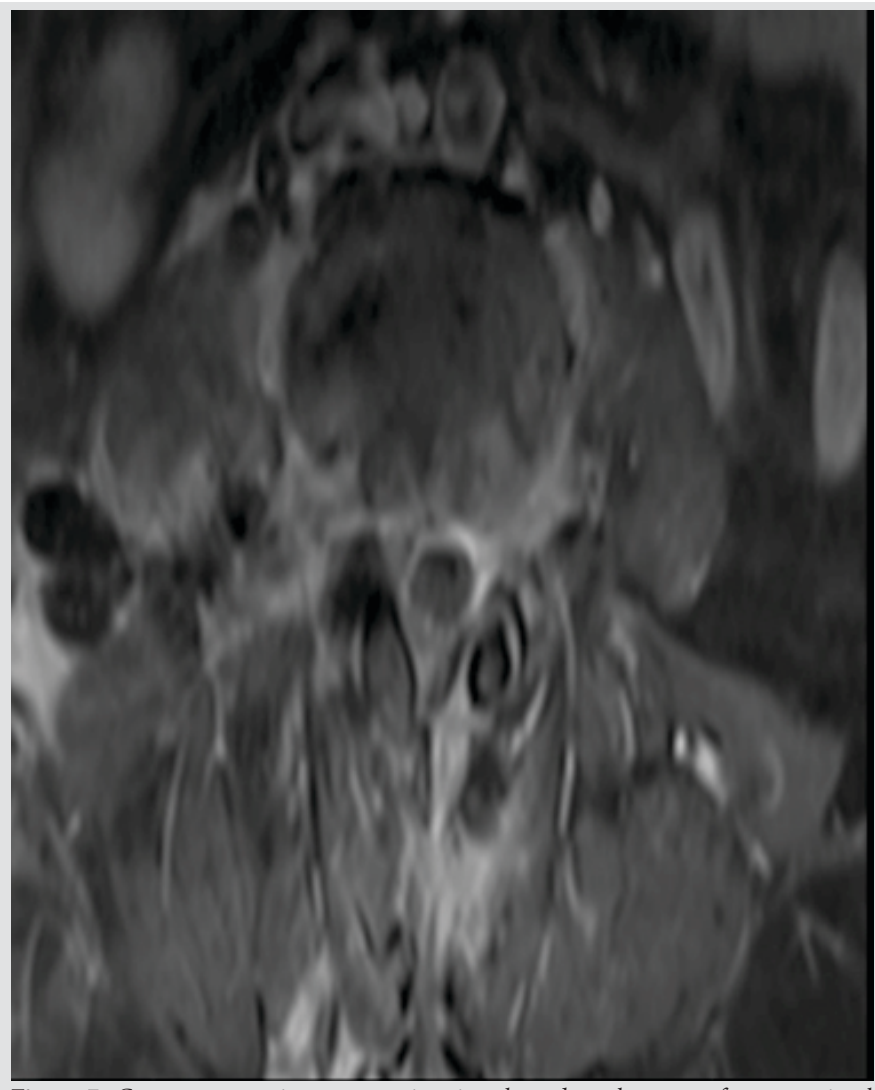

Figure 7: Contrast magnetic resonance imaging showed patchy areas of marrow signal abnormality L1, L2, L4, and L5 vertebra and adjoining endplates of L5, S1, S2 segments. Ring enhancing lesions at L2 and L3 levels. Enhancing hyperintense signals in posterior paraspinal muscles at $\mathrm{L} 1$ and $\mathrm{L} 2$. Tiny enhancing lesions on the right ilium.

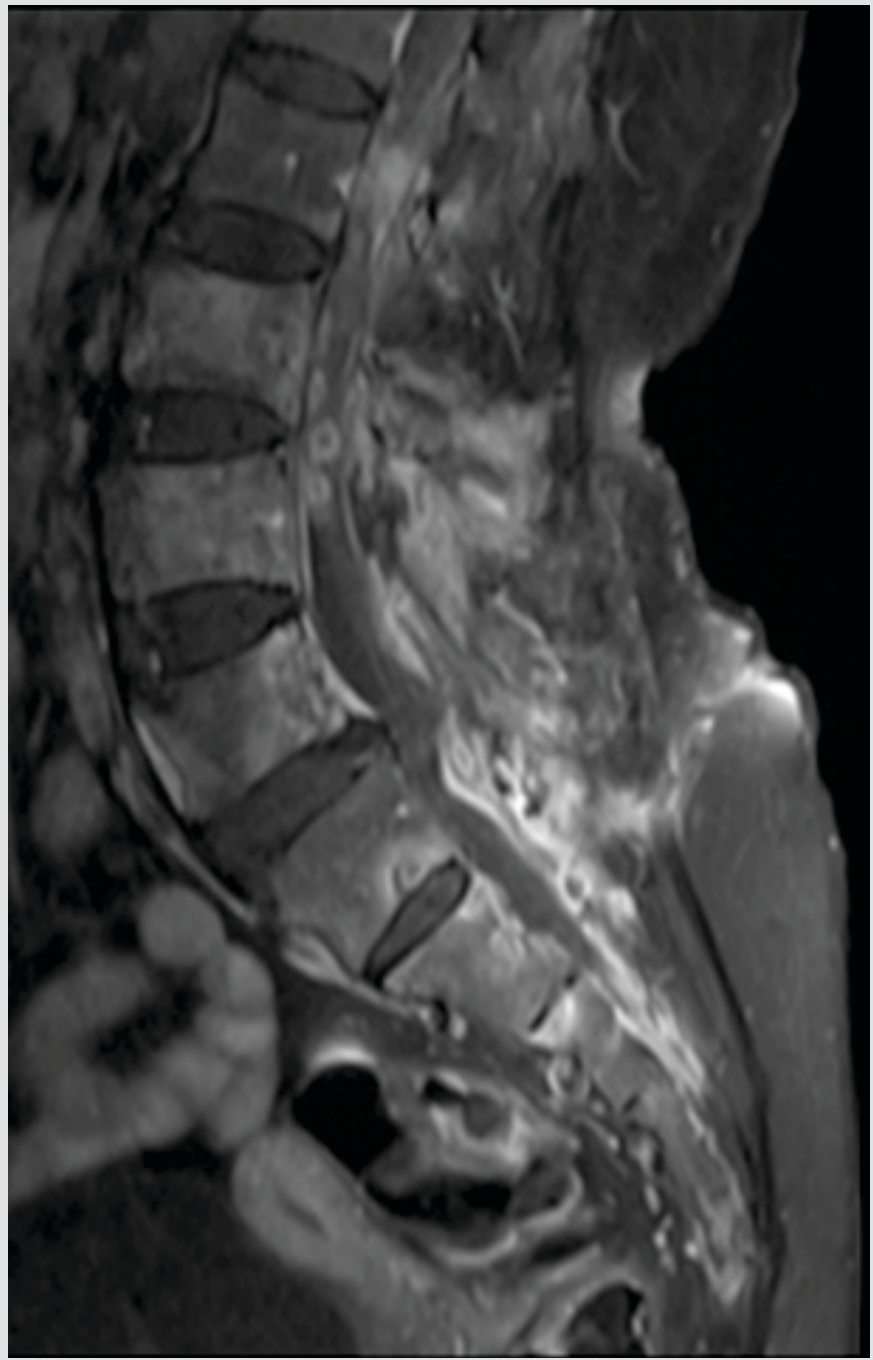

Figure 6: Contrast magnetic resonance imaging showed patchy areas of marrow signal abnormality L1, L2, L4, and L5 vertebra and adjoining endplates of L5, S1, and S2 segments. Ring enhancing lesions at L2 and L3 levels. Enhancing hyperintense signals in posterior paraspinal muscles at L1 and L2. Tiny enhancing lesions on the right ilium.

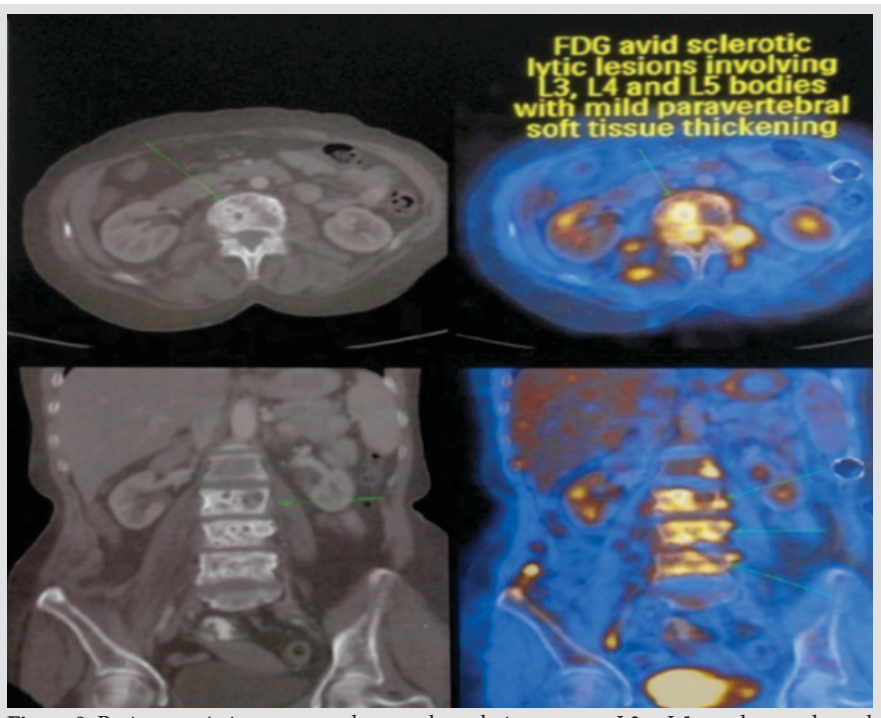

Figure 8: Positron emission tomography scan shows lytic areas over L2 to L5 vertebrae and sacral ala and ilium possibility of infective etiology more likely atypical Kochs/brucella/Fungal or any unusual bacterial infection. 


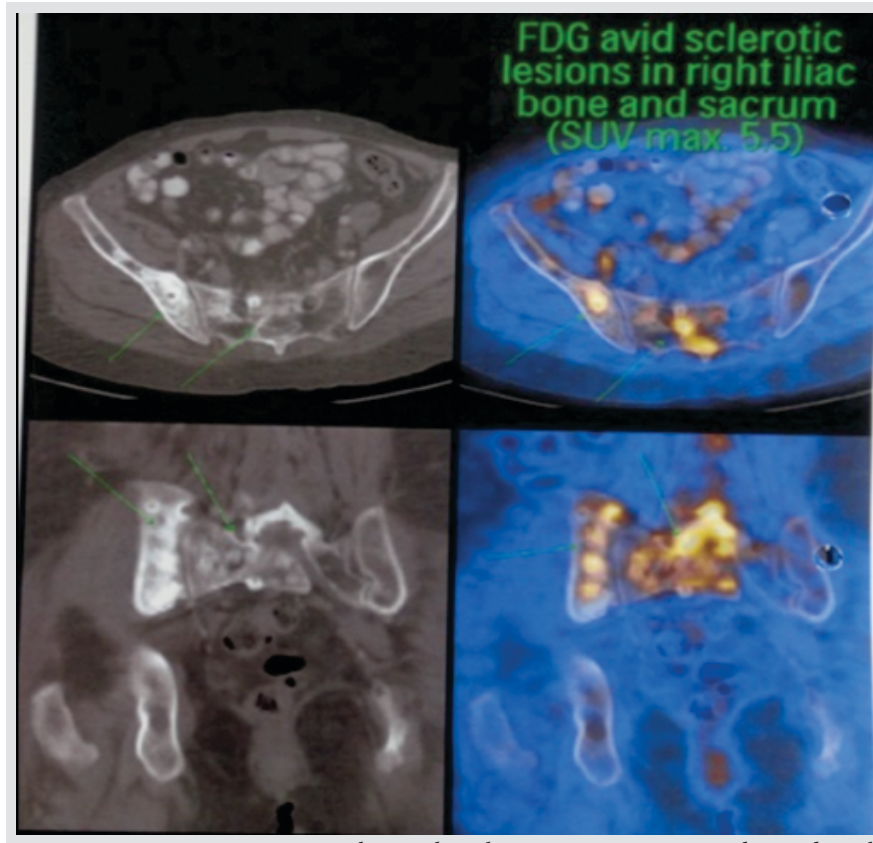

Figure 9: Positron emission tomography scan shows lytic areas over L2 to L5 vertebrae and sacra ala and ilium possibility of infective etiology more likely atypical Kochs/brucella/Fungal or any unusual bacterial infection.

surgical decompression and biopsy from the affected areas. Surgery was performed in the form of laminectomy and decompression by posterior approach and tissue was collected from the right sacral ala. As the pre-operative and intraoperative findings did not favor instability, no instrumented fusion was planned. Histopathological report showed negative metastasis. Microbiology was negative. The patient improved during post-operative period in terms of pain and mobility. VAS scores improved to 4 . After 3 months' post-surgery, the patient came back to the clinic with chief complaints of burning sensations in legs and inability to walk and stand for long with discharging sinuses over the back with the similar neurologi-cal

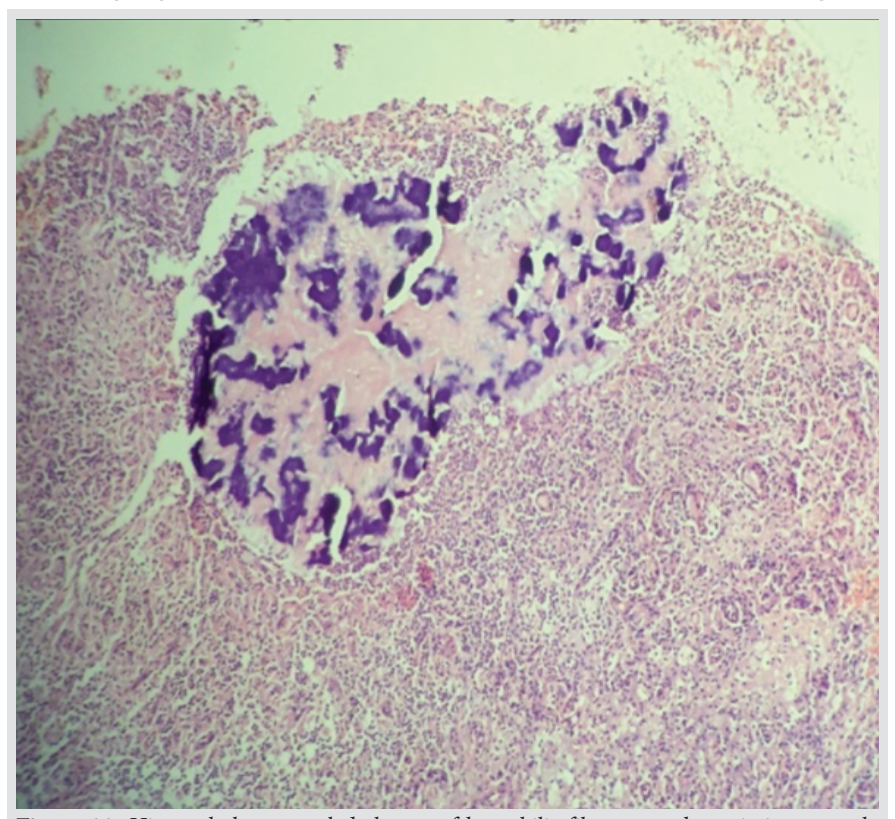

Figure 11: Histopathology revealed clumps of basophilic filamentous bacteria in a vaguely rosette-like configuration surrounded by acute inflammatory cells, characteristic of actinomycosis.

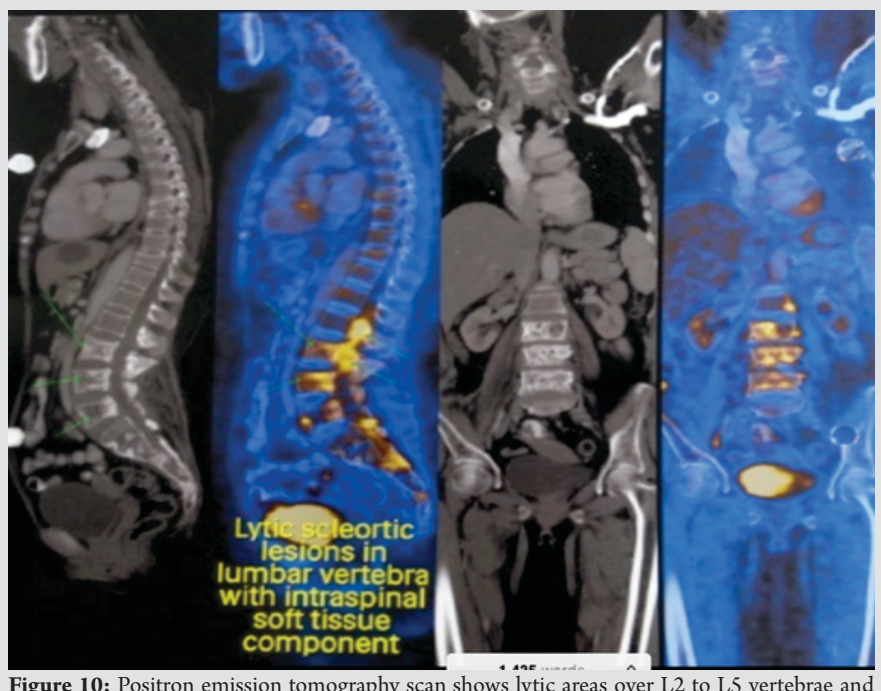

Figure 10: Positron emission tomography scan shows lytic areas over L2 to L5 vertebrae and sacral ala and ilium possibility of infective etiology more likely atypical Kochs/brucella/Fungal or any unusual bacterial infection.

profile.

X-ray (Fig. 4) revealed diffuse osteopenia with patchy sclerosis and degenerative changes with lami-nectomy defects.

Contrast MRI (Fig. 5, 6, 7) showed patchy areas of marrow signal abnormality L1, L2, L4, and L5 vertebra and adjoining endplates of L5, S1, and S2 segments. Ring enhancing lesions at L2, L3 levels. Enhancing hyperintense signals in posterior paraspinal muscles at L1-L2. Tiny enhancing lesions on the right ilium. PET scan (Fig. 8, 9, 10) shows lytic areas over L2 to L5 vertebrae and sacral ala and ilium possibility of infective etiology more likely atypical Kochs/brucella/Fungal or any unusual bacterial infection. A progressively increasing in ESR and CRP directed toward an infective etiology. Tests for brucellosis were negative [7].

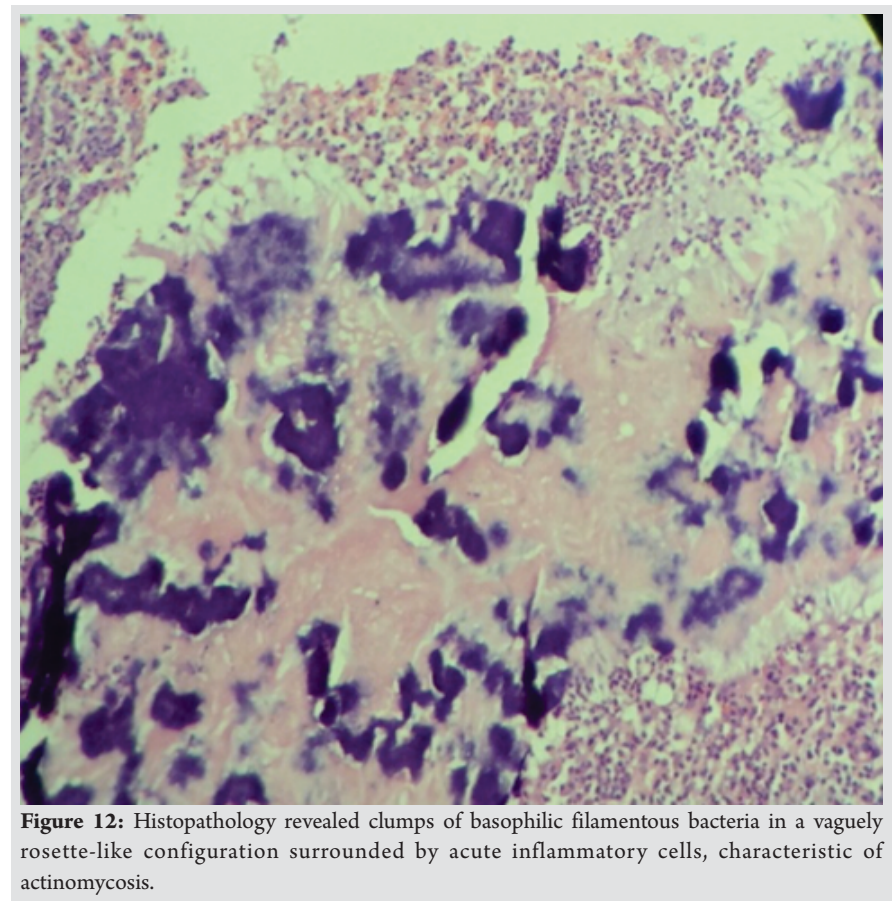




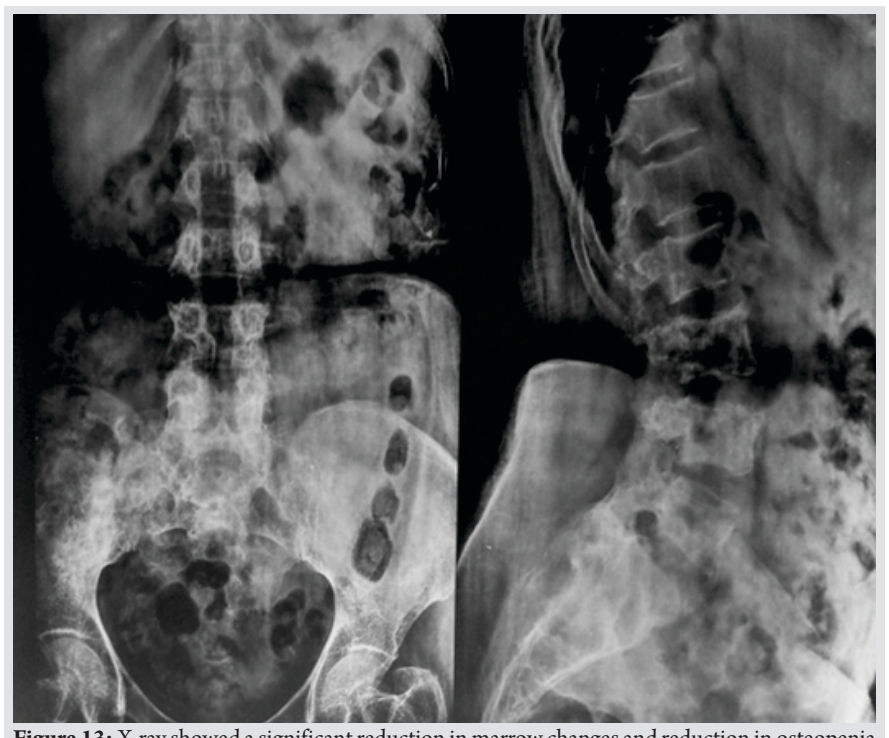

Figure 13: X-ray showed a significant reduction in marrow changes and reduction in osteopenia in lumbar and sacral areas.

The patient underwent repeat surgery in the form of revision decompression. Intraoperatively, there was a thick and hard epidural tissue engulfing the cord and the nerve roots. This unhealthy granulation tissue was carefully removed and sent for analysis. Histopathology (Fig. 11, 12) revealed clumps of basophilic filamentous bacteria in a vaguely rosette-like configuration surrounded by acute inflam-matory cells, characteristic of actinomycosis.

The patient was started on intravenous penicillin G for 4 weeks and followed by oral penicillin for 2 weeks. Wound completely healed by primary intention by 2 weeks. The patient ambulated unassisted with back VAS of 2. Leg VAS reduced to 1 .

After 6 weeks, ODI was 16, X Rays (Fig. 13) showed reduced osteopenia, and MRI showed a signifi-cant reduction in marrow signal abnormalities in lumbar and sacral areas (Fig. 14, 15, 16).

At 6 months, we reviewed the patient again. He had complaints

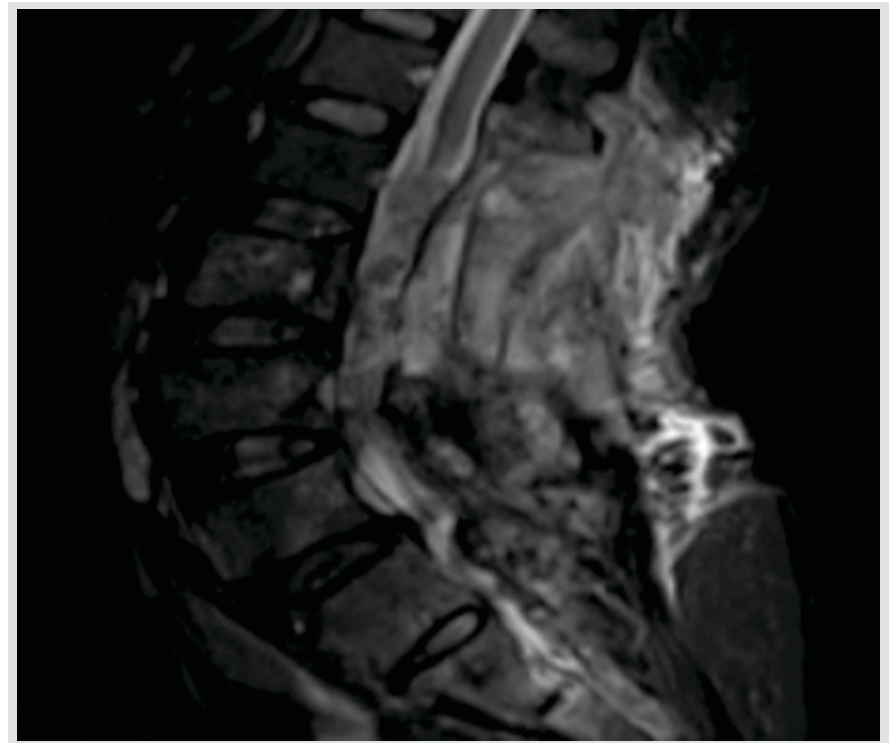

Figure 15: Magnetic resonance imaging showed a significant reduction in marrow signal abnormalities in lumbar and sacral areas.

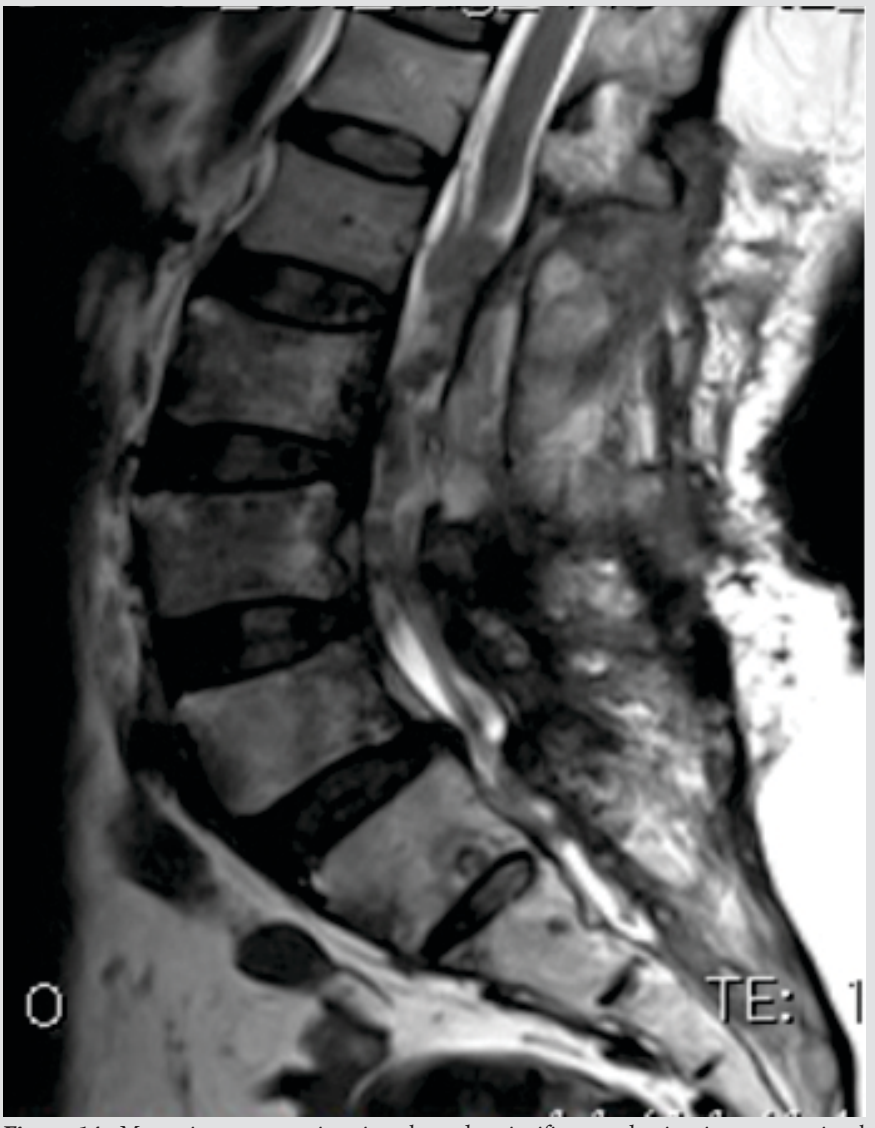

Figure 14: Magnetic resonance imaging showed a significant reduction in marrow signal abnormalities in lumbar and sacral areas.

of back pain, but the examination did not reveal any positive findings.

At 12 months, the patient was asymptomatic.

\section{Discussion}

Actinomycosis, once considered fatal infectious disease, is quite challenging to diagnose actinomycosis as it is known for mimicking other diseases like malignancies $[8,9,10,11]$. Actinomycosis is a chronic suppurative infection caused by

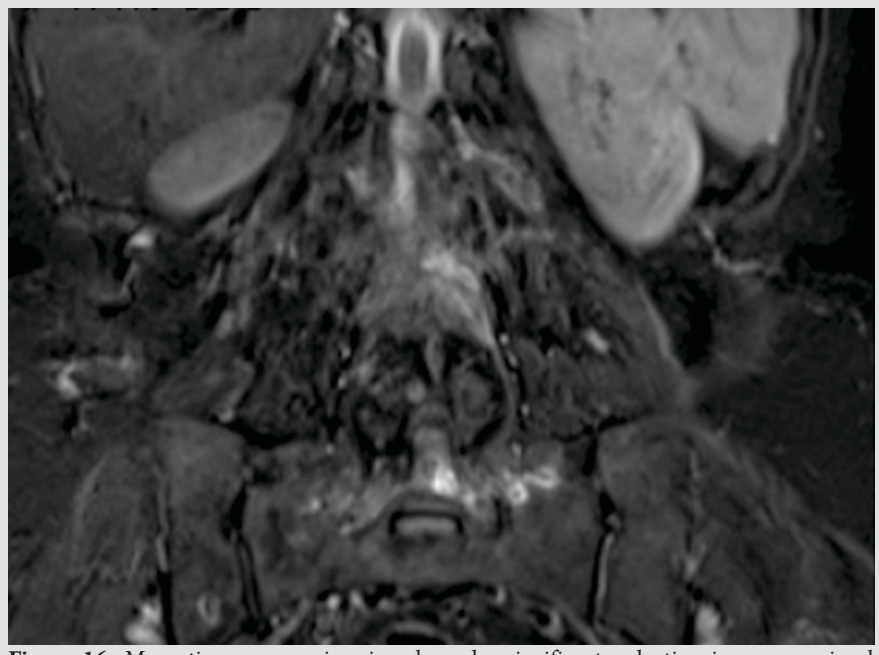

Figure 16: Magnetic resonance imaging showed a significant reduction in marrow signal abnormalities in lumbar and sacral areas. 
actinomyces species which are facultative anaerobic, Grampositive, and acid negative bacilli. These species mainly reside in the oropharyngeal cavity. It is char-acterized by abscess formation, tissue fibrosis, and draining sinuses that discharge sulfur granules. Most common type is Actinomyces israelii [12, 13].

Most classical presentation is cervicofacial form followed by thoracic, abdominopelvic, and cerebral localizations. Actinomycosis organisms are not virulent. They require a break in the integrity in mucous membranes and presence of devitalized tissues to invade deeper body structures. Once infection sets in, the host mounts an intense inflammatory response followed by fibrosis. Infection spreads con-tiguously invading surrounding tissues and organs, leading to draining sinus tracts. Vertebral actino-mycosis can be due to hematogenous spread [14]. Due to the slow progress of the disease, new bone formation as well as bone destruction can be visualized. As the disease progresses, initial erosions be-come deeper and causing destruction of cancellous bone causing multiple intercommunicating cystic spaces. These cystic spaces give a mottled or lattice appearance on imaging. One or several adjacent vertebrae may be affected with paraspinal and subcutaneous abscesses. Complications due to vertebral

\section{References}

1. Mackenzie AR, Laing RB, Smith CC, Kaar GF, Smith FW. Spinal epidural abscess: The im-portance of early diagnosis and treatment. J Neurol Neurosurg Psychiatry 1998;65:209-12.

2. Kim DM, Kim SW. Destruction of the C2 body due to cervical actinomycosis: Connection be-tween spinal epidural abscess and retropharyngeal abscess. Korean J Spine 2017;14:20-2.

3. Yung BC, Cheng JC, Chan TT, Loke TK, Lo J, Lau PY. Aggressive thoracic actinomycosis complicated by vertebral osteomyelitis and epidural abscess leading to spinal cord compression. Spine (Phila Pa 1976) 2000;25:745-8.

4. Maeder PP, Ingvar-Maeder MC, Meuli RA, Regli F, De Tribolet N. Cervical epidural abscess due to actinomycosis: Demonstration by MRI. Eur Neurol 1996;36:56-7.

5. Tang HJ, Lin HJ, Liu YC, Li CM. Spinal epidural abscess-experience with 46 patients and evaluation of prognostic factors. J Infect 2002;45:76-81.

6. Kou J, Fischgrund J, Biddinger A, Herkowitz H. Risk factors for spinal epidural hematoma af-ter spinal surgery. Spine (Phila Pa 1976) 2002;27:1670-3. actinomycosis can be meningitis, epidural abscess, and spinal cord compression. Sulfur granules from discharging sinus and histopathology are diagnostic for actinomycosis [15]. Penicillin therapy is the mainstay treatment for actinomycosis [16]. Newer drugs such as ceftriaxone, ceftizoxime, imipenem, and ciprofloxacin are considered successful in treatment of actinomycosis.

\section{Conclusion}

Spinal infections are often taken as Pott's spine, and empirically started on ATT. Actinomycotic infec-tions of the spine are rare cause of spinal infections but should be kept in mind once the tubercular in-fection is ruled out. The definitive diagnosis of actinomycosis can be made by finding actinomycetes in the pus from affected tissue.

\section{Clinical Message}

Actinomycotic spinal infection can mimic tuberculosis. High clinical suspicion and tissue diagnosis are essential in the complete and appropriate treatment of infective spondylodiscitis.
7. Araj GF, Brown GM, Haj MM, Madhvan NV. Assessment of brucellosis card test in screening patients for brucellosis. Epidemiol Infect 1988; 100:389-98.

8. Hwang JH, Song SH, Kim KA, Shin BK, Lee JK, Lee NW, et al. Primary serous papillary car-cinoma of the peritoneum mimicking pelvic actinomycosis: A case report and brief literature review. Eur J Gynaecol Oncol 2010;31:214-6.

9. Radha P, Condon A, Yong Kuei TL. M312 case report of pelvic actinomycosis presenting as a complex pelvic mass suspicious for malignancy. Int J Gynecol Obstetr 2012;119:S631-2.

10. Velenciuc N, Velenciuc I, Makkai Popa S, Roată C, Ferariu D, Luncă S. Pelvic actinomycosis mimicking a locally advanced pelvic malignancy--case report. Rev Med Chir Soc Med Nat Iasi 2016;120:393-9.

11. Prajapati S, Yoon DJ, Benitez CL, Buyuk A. Cervical vertebral actinomycosis mimicking ma-lignancy in a paediatric patient. B M C a s e Rep 2016;2016:bcr2016214757.

12. Moniruddin AB, Begum H, Nahar K. Actinomycosis: An update. Med Today 2012;21:38-42.

13. Duvignaud A, Ribeiro E, Moynet D, Longy-Boursier M, Malvy D. Cervical spondylitis and spinal abscess due to 
Actinomyces meyeri. BrazJ Infect Dis 2014;18:106-9.

14. Thango NS, Kamat A, Ben Husein M, Welsh D. Retraction:

Thoracic vertebral actinomycosis secondary to a pulmonary origin. Cureus 2018;10:r10.
15. Vikas C. Spinal actinomycosis. J Dr NTR Univ Health Sci 2014;3:122.

16. Cope VZ, Zachary Cope V. The treatment of actinomycosis. In: Human Actinomycosis. Ox-ford: ButterworthHeinemann; 2013.p. 65-9.

\section{Conflict of Interest: Nil \\ Source of Support: Nil}

Consent: The authors confirm that informed consent was obtained from the patient for publication of this case report

\section{How to Cite this Article}

Hadgaonkar S, Rathi P, Vincent V, Shyam A, Sancheti P. Actinomycotic Infection of Spine -A Rare Disease with Diagnostic Challenge, an Update on Spinal Infection. Journal of Orthopaedic Case Reports 2021 January;11(1): 72-78. 